Pesq. Vet. Bras. 37(3):295-299, março 2017 DOI: $10.1590 /$ S0100-736X2017000300015

\title{
Cardiac parameters during the estrous cycle of canine bitches ${ }^{1}$
}

\author{
Rute C.A. de Souza ${ }^{2}$, Regiane Peres ${ }^{3}$, Marlos G. Sousa ${ }^{4}$ and Aparecido A. Camacho ${ }^{3 *}$ \\ ABSTRACT.- Souza R.C.A., Peres R., Sousa M.G. \& Camacho A.A. 2017. Cardiac para- \\ meters during the estrous cycle of canine bitches. Pesquisa Veterinária Brasileira \\ 37(3):295-299. Faculdade de Ciências Agrárias e Veterinárias, Universidade Estadual \\ Paulista, Unesp-Jaboticabal, Via de Acesso Prof. Paulo Donato Castellane s/n, Jaboticabal, \\ SP 14870-000, Brazil, E-mail: camacho@fcav.unesp.br \\ The cardiovascular parameters of canine bitches were assessed during the estrous \\ cycle. A total of eleven mongrel female dogs were enrolled in a longitudinal prospective in- \\ vestigation. Six animals were bred during the study and were assigned into group I, in whi- \\ ch evaluations were performed during proestrus, estrus, gestational diestrus and anestrus. \\ The five remaining bitches were not bred and underwent evaluations during proestrus, \\ estrus, nongestational diestrus and anestrus. The holter data showed a gradual increase in \\ the minimum and mean heart rate along pregnancy, as well as a reduction during anestrus, \\ which differed significantly among the distinct periods. The values for maximal heart rate \\ documented during pregnancy were significantly lower than those recorded during anes- \\ trus, and a variation in the heart rate circadian rhythm was also found, as demonstrated by \\ decreases at night and rises during the day. Cardiac rhythm had a similar performance in \\ both pregnancy and anestrus. Likewise, the blood pressure, electrocardiography, and echo- \\ cardiography data did not vary during the estrous cycle. The results support the role played \\ by the autonomic nervous system during these two distinct periods in order to attain a \\ heart rate that provides the blood needed by the female's body during the various stages \\ of the reproductive cycle. Further studies are needed to better clarify the cardiovascular \\ compensatory neuroendocrine events that accompany gestation in this species.
}

INDEX TERMS: Cardiac parameters, estrous cycle, bitches, cardiovascular system, reproductive cycle, pregnancy, dog.

RESUMO.- [Parâmetros cardíacos durante o ciclo estral de cadelas.] Os parâmetros cardiovasculares de fêmeas caninas foram avaliados durante o ciclo estral. Um total de onze cadelas sem raça definida foram incluídas nesta pesquisa prospectiva longitudinal. Seis animais foram colocados em reprodução durante o estudo e avaliados durante o proestro, estro, diestro gestacional e anestro. As cinco cadelas restantes não se reproduziram e foram avaliadas durante o proestro, estro, diestro não gestacional e anestro. Os dados derivados do holter indicaram aumento gradativo nas frequências

\footnotetext{
${ }^{1}$ Received on June 24, 2015.

Accepted for publication on August 16, 2016.

${ }^{2}$ Universidade Federal Rural de Pernambuco (UFRPE), Avenida Bom Pastor s/n, Mundaú, Garanhuns, PE 55292-270, Brazil

${ }^{3}$ Universidade Estadual Paulista (Unesp), Via de Acesso Prof. Paulo Donato Castellane s/n, Jaboticabal, SP 14870-000, Brazil

${ }^{4}$ Universidade Federal do Paraná (UFPR), Rua dos Funcionários 1540, Cabral, Curitiba, PR 80035-050, Brazil. *Corresponding author: camacho@ fcav.unesp.br
}

cardíacas mínima e média durante a gestação, bem como redução durante o anestro, diferindo significativamente entre os distintos períodos. Os valores da frequência cardíaca máxima documentados durante a gestação foram significativamente inferiores àqueles registrados durante $o$ anestro. Também foi identificada variação no ritmo circadiano da frequência cardíaca, conforme demonstrado por sua redução à noite e elevação durante o dia. No entanto, o ritmo cardíaco se comportou de modo semelhante tanto na gestação quanto no anestro. Da mesma forma, os dados de pressão sanguínea, eletrocardiografia e ecocardiografia não variaram durante o ciclo estral. Os resultados atestam o papel desempenhado pelo sistema nervoso autônomo ao longo desses dois períodos distintos, visando manter uma frequência cardíaca que garanta o suprimento sanguíneo necessário pelo organismo da fêmea durante os vários estágios do ciclo reprodutivo. Estudos adicionais são necessários para esclarecer mais detalhadamente os eventos neuroendócrinos e cardiovasculares compensatórios que acompanham a gestão nessa espécie. 
TERMOS DE INDEXAÇÃO: Parâmetros cardíacos, ciclo estral, cadelas, sistema cardiovascular, ciclo reprodutivo, gestação, cão.

\section{INTRODUCTION}

Hemodynamic changes during pregnancy are complex in all mammals, with the additional blood supply required by the uterus, fetus, and mammary glands being added to the physiological blood demand of other organs. Some of these changes, including an increase in plasma volume, cardiac output (CO), stroke volume, and heart rate (HR), are attributable to the effects of sex and pregnancy hormones, as well as other neuroendocrine factors (Horwitz \& Horwitz 1982).

Besides the elevation in $\mathrm{HR}, \mathrm{CO}$, and blood volume, other physiological responses of the heart that are associated with gestation in women might be similar in pregnant dogs and cats, such as the reduction in cardiac reserve without any changes in arterial pressure and central venous pressure. The decline in cardiac reserve was shown to occur near the final stage of pregnancy, being ascribed to the elevated intravascular volume and HR, therefore resulting in an increased risk of decompensation or cardiac failure (Greene 1995).

In human beings, the cardiovascular alterations associated with both pregnancy and female sex hormones are a quite common concern. In animals, some studies have been carried out to elucidate these physiological changes. Nevertheless, the estrous cycle of dogs and other animals differs from the reproductive cycle of women, demanding studies that allow comparing the role played by hormones on the cardiovascular parameters of different species. Therefore, this study was aimed at investigating the effects of pregnancy and the phases of the reproductive cycle on the cardiovascular parameters of dogs.

\section{MATERIALS AND METHODS}

Eleven adult (30-86 months) mixed-breed healthy bitches, with mean body weight of $12.4 \pm 4.2 \mathrm{~kg}$, were recruited from the university's experimental kennel for a prospective longitudinal study. Inclusion criteria included a normal physical examination, as well as the results of hematological tests and cardiovascular exams (including electrocardiogram, echocardiogram, chest radiograph, and arterial pressure) being within the normal range for the species. All dogs were housed in wards and provided with water and commercially-available dog food ad libitum for the whole experimental period. Some of the bitches were bred during the study and composed group I $(n=6)$, while the remainder did not breed and were assigned into group II $(n=5)$. A 36-hour interval was allowed for each of group I bitches to breed along the preceding estrus in order to obtain the gestational diestrus. For this purpose, three male dogs were used randomly. The study was entirely conducted in accordance with the guidelines outlined in the National Institutes of Health Guide for the Care and Use of Laboratory Animals, and was previously approved by the institutional committee on the ethics and animal welfare under protocol 9147.

The animals of group I were evaluated at four-day intervals during the proestrus and estrus. During gestational diestrus, the exams were performed at seven-day intervals until delivery. During anestrus, assessment was undertaken at the first day post-delivery, following weekly assessments for 30 days, and monthly assessments until the end of the reproductive cycle, as demonstra-

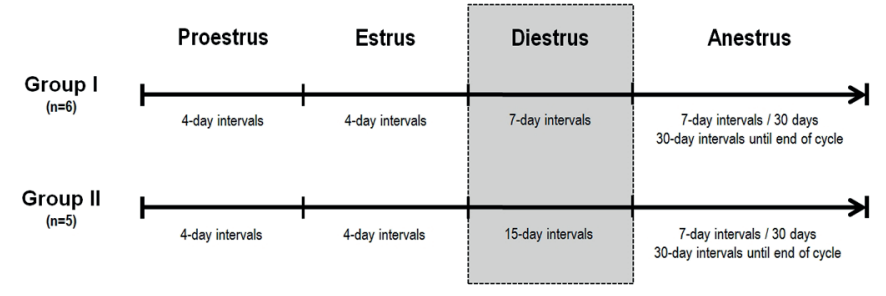

Fig.1. Schematic drawing that illustrates the time intervals in which assessments were undertaken at every phase of the estrous cycle of the bitches included in either group I or group II. The ones assigned to group I were bred and therefore the gestational diestrus was present, while animals not bred were included in group II, with the non-gestational diestrus evaluated instead.

ted by both physical examination and vaginal cytology. The same protocol was used to assess group II animals during proestrus, estrus, and anestrus. During non-gestational diestrus, however, the animals were evaluated at 15-day intervals (Fig. 1). Both physical examination and vaginal cytology were used for the identification of the phases of the estrous cycle (Vannucchi et al. 1997), and the diagnosis of pregnancy was made by abdominal ultrasonography at approximately 30 days after the last breeding.

To measure the arterial pressure the animals were maintained in right lateral recumbency, with the cuff positioned around the distal left humerus, next to the elbow. An oscillometric non-invasive blood pressure equipment was used, providing three approximate results of systolic, mean, and diastolic blood pressures (Hansen 1995). The ideal width and length of the cuff was determined as $40 \%$ and 1.5-fold, respectively, of each animal's limb circumference (Murray 1998).

The echocardiograms were performed with the dogs standing, using an ultrasound machine equipped with a $5.0 \mathrm{MHz}$ transducer. M-mode images were obtained, which allowed the measurement of the left-ventricular diameter both in systole and diastole, and to calculate the systolic and diastolic left-ventricular volumes (with the Teichholz equation), the left-ventricular ejection time, the ejection fraction, the stroke volume, and the cardiac output (Boon \& Wingfield 1983, Kienle \& Thomas 1995, Miller 1998, Ware 1998).

A computer-based electrocardiograph was used to simultaneously record ECG tracings in leads I, II, III, aVR, aVL, aVF, rV2, V2, $\mathrm{V} 4$, and V10, at a paper speed of $50 \mathrm{~mm} / \mathrm{s}$ and vertical calibration of $1 \mathrm{~cm} / \mathrm{mV}$ (Tilley 1992, Wolf at al. 2000). Holter electrocardiography was done in only five subjects of group I at days 20,40, and 55 after the last breeding day, as well as at the second third of the anestrus. In these cases, cardiac rhythm was recorded for 24 hours from two chest leads (rV2 and V4) using a holter device, whose recordings were decoded to determine the minimal, mean, and maximal heart rates, as well as the circadian rhythm of heart rate.

Neither sedatives nor anesthesia were used during the assessment of blood pressure, echocardiogram and ECG of the animals.

Statistical analysis of the quantitative data involved a subdivided parcels design, with the Tukey test used to compare means (Banzatto \& Kronka 1992). Also, gestational and non-gestational diestrus were analyzed as subdivided parcels. A chi-square test was used to assess the qualitative data (Gomes 1987), looking for independence of the tested parameters in relation to the phases of the estrous cycle. Data from holter electrocardiography was treated as a randomized-block (animals), with the Tukey test used to compare the means (Banzatto \& Kronka 1992). All analyses were performed using the software Statistical Analysis System (PROC GLM - SAS), with the probability $<0.05$ considered to be significant. 


\section{RESULTS}

This investigation found systolic, mean, and diastolic arterial pressures within the normal limits described in literature (Murray 1998), attaining no statistical differences regarding the estrous cycle or between groups (Table 1). Also, no differences were documented on the echocardiographic data along the various phases of the estrous cycle (Table 2), with the data fitting within the normal range for the species (Boon \& Wingfield 1983, Kienle \& Thomas 1995).

On the contrary, the electrocardiogram (Table 3 and 4) demonstrated a progressive reduction of $\mathrm{P}$ wave amplitude during gestation, with the lowest values being recorded at the final third, which was significantly different $(\mathrm{p}<0.01)$ from the first and third thirds of the gestational diestrus. For group II, these values remained constant during the whole phase, although a significant difference $(\mathrm{p}<0.01)$ was observed in regard to group I animals at the final third of diestrus. The QRS complex duration was above the normal range at GII, producing a difference $(\mathrm{p}<0.05)$ from GI

Table 1. Mean and standard-deviation of the oscillometric blood pressure (systolic, mean and diastolic) obtained in bitches of groups I $(n=6)$ and II $(n=5)$ during the estrous cycle

\begin{tabular}{lccccc}
\hline Parameters & Group & \multicolumn{4}{c}{ Estrous cycle phases } \\
\cline { 3 - 6 } & & Proestrus & Estrus & Diestrus & Anestrus \\
\hline SAP & & $149 \pm 10$ & $145 \pm 10$ & $140 \pm 10$ & $140 \pm 7$ \\
(mmHg) & I & $137 \pm 8$ & $142 \pm 3$ & $141 \pm 3$ & $141 \pm 3$ \\
& II & & & & \\
MAP & & $98 \pm 15$ & $96 \pm 10$ & $98 \pm 11$ & $96 \pm 8$ \\
(mmHg) & I & $94 \pm 6$ & $97 \pm 4$ & $98 \pm 7$ & $94 \pm 6$ \\
DAP & II & & & & \\
(mmHg) & I & $74 \pm 14$ & $73 \pm 10$ & $74 \pm 12$ & $73 \pm 12$ \\
& II & $69 \pm 11$ & $69 \pm 9$ & $66 \pm 7$ & $68 \pm 10$
\end{tabular}

$\overline{\mathrm{SAP}}=$ systolic arterial pressure; $\mathrm{MAP}=$ mean arterial pressure; $\mathrm{DAP}=$ diastolic arterial pressure. No difference existed between phases of reproductive cycle, as well as between groups.

Table 2. Mean and standard-deviation of the M-mode derived echocardiographic data documented in bitches of groups I $(n=6)$ and II $(n=5)$ during the estrous cycle

\begin{tabular}{lccccc}
\hline Parameters & Group & \multicolumn{4}{c}{ Estrous cycle phases } \\
\cline { 2 - 6 } & & Proestrus & Estrus & Diestrus & Anestrus \\
\hline LVDd (mm) & I & $30.3 \pm 1.7$ & $30.5 \pm 1.4$ & $30.6 \pm 2.3$ & $30.4 \pm 1.1$ \\
& II & $30.6 \pm 1.6$ & $29.5 \pm 2.5$ & $30.0 \pm 1.7$ & $29.2 \pm 2.1$ \\
LVDs (mm) & I & $21.1 \pm 1.7$ & $20.4 \pm 0.7$ & $20.3 \pm 2.0$ & $19.8 \pm 1.1$ \\
& II & $20.9 \pm 2.4$ & $19.5 \pm 2.3$ & $20.7 \pm 1.9$ & $20.1 \pm 2.1$ \\
LVVd (mL) & I & $59.7 \pm 7.1$ & $60.5 \pm 5.8$ & $61.5 \pm 9.9$ & $60.4 \pm 4.4$ \\
& II & $60.9 \pm 4.9$ & $56.7 \pm 9.5$ & $58.5 \pm 6.8$ & $55.6 \pm 8.1$ \\
LVVs (mL) & I & $28.1 \pm 4.9$ & $26.2 \pm 2.0$ & $26.4 \pm 4.5$ & $24.7 \pm 2.9$ \\
& II & $27.9 \pm 7.2$ & $24.5 \pm 5.4$ & $27.2 \pm 5.2$ & $25.6 \pm 5.7$ \\
SV (mL) & I & $31.6 \pm 2.9$ & $34.3 \pm 4.0$ & $35.0 \pm 5.2$ & $35.7 \pm 3.1$ \\
& II & $33.0 \pm 3.4$ & $31.3 \pm 3.4$ & $32.6 \pm 4.6$ & $29.9 \pm 5.7$ \\
EF (\%) & I & $52 \pm 4$ & $56 \pm 2$ & $57 \pm 4$ & $59 \pm 3$ \\
& II & $54 \pm 8$ & $57 \pm 4$ & $54 \pm 5$ & $55 \pm 7$ \\
CO (L/min) & I & $3.72 \pm 0.89$ & $3.96 \pm 0.98$ & $4.01 \pm 0.76$ & $4.16 \pm 0.23$ \\
& II & $3.69 \pm 0.67$ & $3.66 \pm 0.96$ & $3.52 \pm 0.49$ & $3.48 \pm 0.74$
\end{tabular}

$\overline{\mathrm{LVDd}}=$ left-ventricular diameter at diastole; LVDs = left-ventricular diameter at systole; LVVd = left-ventricular volume at diastole; LVVs = left-ventricular volume at systole; $\mathrm{SV}=$ stroke volume; $\mathrm{EF}=$ ejection fraction; $\mathrm{CO}=$ cardiac output. No difference existed between phases of reproductive cycle, as well as between groups.
Table 3. Mean and standard-deviation of the quantitative ECG parameters obtained in bitches of groups I $(n=6)$ and II $(n=5)$ during the estrous cycle

\begin{tabular}{lccccc}
\hline Parameters & Group & \multicolumn{4}{c}{ Estrous cycle phases } \\
\cline { 2 - 6 } & & Proestrus & Estrus & Diestrus & Anestrus \\
\hline HR (bpm) & I & $115 \pm 21$ & $115 \pm 17$ & $118 \pm 12$ & $112 \pm 15$ \\
& II & $128 \pm 6$ & $117 \pm 12$ & $131 \pm 14$ & $125 \pm 20$ \\
P (ms) & I & $33 \pm 5$ & $35 \pm 3$ & $36 \pm 3$ & $36 \pm 4$ \\
& II & $34 \pm 4$ & $38 \pm 2$ & $34 \pm 3$ & $34 \pm 2$ \\
PR (ms) & I & $88 \pm 10$ & $93 \pm 10$ & $93 \pm 10$ & $89 \pm 8$ \\
& II & $92 \pm 7$ & $87 \pm 8$ & $91 \pm 12$ & $88 \pm 9$ \\
QRS (ms) & I & $52 \pm 6^{\text {Aa }}$ & $50 \pm 8^{\text {Ba }}$ & $50 \pm 3^{\text {Aa }}$ & $51 \pm 2^{\text {Aa }}$ \\
& II & $54 \pm 6^{\text {Aa }}$ & $60 \pm 2^{\text {Aa }}$ & $55 \pm 7^{\text {Aa }}$ & $51 \pm 5^{\text {Aa }}$ \\
QT (ms) & I & $185 \pm 13$ & $198 \pm 15$ & $199 \pm 11$ & $198 \pm 17$ \\
& II & $190 \pm 6$ & $193 \pm 17$ & $190 \pm 9$ & $188 \pm 4$ \\
P (mV) & I & $0.24 \pm 0.07$ & $0.25 \pm 0.05$ & $0.20 \pm 0.05$ & $0.21 \pm 0.04$ \\
& II & $0.25 \pm 0.05$ & $0.23 \pm 0.03$ & $0.24 \pm 0.04$ & $0.27 \pm 0.05$ \\
R (mV) & I & $1.91 \pm 0.50$ & $1.96 \pm 0.45$ & $1.67 \pm 0.31$ & $1.61 \pm 0.37$ \\
& II & $1.49 \pm 0.41$ & $1.45 \pm 0.39$ & $1.30 \pm 0.41$ & $1.35 \pm 0.29$ \\
MEA (degrees) & I & $69 \pm 20$ & $72 \pm 11$ & $71 \pm 12$ & $76 \pm 10$ \\
& II & $66 \pm 8$ & $67 \pm 10$ & $63 \pm 6$ & $64 \pm 14$
\end{tabular}

$\mathrm{HR}$ = ECG-derived heart rate; $\mathrm{ms}=$ miliseconds; $\mathrm{mV}=$ millivolts; $\mathrm{MEA}=$ mean electrical axis. Different uppercase letters indicate significant differences $(\mathrm{p}<0.05)$ between groups at the Tukey test analysis.

Different lowercase letters indicate significant diferences $(\mathrm{p}<0.05)$ between the phases of the estrous cycle within a single group at the Tukey test analysis.

Table 4. Mean and standard-deviation of the qualitative ECG parameters obtained in bitches of groups I $(n=6)$ and II $(n=5)$ at the thirds of diestrus

\begin{tabular}{lcccc}
\hline Parameters & Group & \multicolumn{3}{c}{ Thirds of diestrus } \\
\cline { 2 - 5 } & & 1 st & 2nd & 3rd \\
\hline HR (bpm) & I & $119 \pm 17$ & $116 \pm 16$ & $119 \pm 14$ \\
& II & $127 \pm 15$ & $132 \pm 26$ & $135 \pm 8$ \\
P (ms) & I & $34 \pm 3$ & $36 \pm 3$ & $36 \pm 4$ \\
& II & $34 \pm 3$ & $33 \pm 4$ & $37 \pm 4$ \\
PR (ms) & I & $94 \pm 12$ & $96 \pm 10$ & $88 \pm 10$ \\
& II & $90 \pm 16$ & $92 \pm 13$ & $89 \pm 9$ \\
QRS (ms) & I & $49 \pm 7$ & $50 \pm 5$ & $51 \pm 1$ \\
& II & $58 \pm 8$ & $54 \pm 6$ & $53 \pm 11$ \\
QT (ms) & I & $201 \pm 14$ & $201 \pm 11$ & $195 \pm 11$ \\
& II & $194 \pm 15$ & $190 \pm 13$ & $189 \pm 5$ \\
P (mV) & I & $0.24 \pm 0.05^{\text {Aa }}$ & $0.21 \pm 0.06^{\text {Aab }}$ & $0.16 \pm 0.05^{\mathrm{Bb}}$ \\
& II & $0.24 \pm 0.04^{\text {Aa }}$ & $0.24 \pm 0.04^{\text {Aa }}$ & $0.25 \pm 0.05^{\text {Aa }}$ \\
R (mV) & I & $1.76 \pm 0.35$ & $1.72 \pm 0.33$ & $1.55 \pm 0.29$ \\
& II & $1.37 \pm 0.46$ & $1.30 \pm 0.46$ & $1.26 \pm 0.33$ \\
MEA (degrees) & I & $73 \pm 14$ & $72 \pm 11$ & $70 \pm 13$ \\
& II & $64 \pm 15$ & $66 \pm 7$ & $59 \pm 6$
\end{tabular}

$\mathrm{HR}=\mathrm{ECG}$-derived heart rate; $\mathrm{ms}=$ miliseconds; $\mathrm{mV}=$ millivolts; MEA: mean electrical axis. Different uppercase letters indicate significant differences $(p<0.05)$ between groups at the Tukey test analysis. Different lowercase letters indicate significant diferences $(p<0.05)$ between the thirds of diestrus within a single group at the Tukey test analysis.

during estrus. All other ECG parameters were within the normal limits.

There was no significant variation in cardiac rhythm. Respiratory sinus arrhythmia (RSA) with wandering pacemaker (RSA/WPM) was more frequent during the estrus and anestrus of group I. However, RSA and RSA/WPM occurred similarly during proestrus. During gestational diestrus (GI), a more homogeneous distribution of rhythms was documented, with RSA and RSA/WPM being more pre- 
Table 5. Mean and standard error of the minimal, mean, and maximal heart rate obtained by 24 -hour holter electrocardiography in bitches of group I $(n=5)$ at 20,40 , and 55 days of gestation, and at the second third of anestrus

\begin{tabular}{lcccc}
\hline Moments of evaluation & \multicolumn{3}{c}{ Heart rate } \\
\cline { 3 - 5 } & & Minimal (bpm) & Mean (bpm) & Maximal (bpm) \\
\hline \multirow{2}{*}{ Gestation } & 20 days & $63 \pm 1^{\mathrm{C}}$ & $82 \pm 1^{\mathrm{D}}$ & $165 \pm 4^{\mathrm{C}}$ \\
& 40 days & $69 \pm 1^{\mathrm{B}}$ & $99 \pm 2^{\mathrm{B}}$ & $177 \pm 3^{\mathrm{B}}$ \\
& 55 days & $80 \pm 1^{\mathrm{A}}$ & $112 \pm 1^{\mathrm{A}}$ & $169 \pm 3^{\mathrm{BC}}$ \\
Anestrus & & $50 \pm 1^{\mathrm{D}}$ & $87 \pm 1^{\mathrm{C}}$ & $212 \pm 2^{\mathrm{A}}$
\end{tabular}

Different uppercase letters in the same column indicate significant differences $(\mathrm{p}<0.05)$ between the moments of evaluation at the Tukey test analysis.

valent. On the other hand, RSA was more common during the estrus, non-gestational diestrus, and anestrus of group II animals, contrasting with the similar prevalence of sinus rhythm and RSA during proestrus. Also, a few cases of sinus tachycardia were observed in some phases of the reproductive cycle. Although there was a marked variation in T wave polarity along the whole estrous cycle, no ST segment shifts have been documented.

The results of holter electrocardiography showed the minimal and mean heart rate to differ significantly $(\mathrm{p}<0.05)$ between the moments of evaluation, as well as a progressive increase along gestation. Also, the maximal heart rate differed $(\mathrm{p}<0.05)$ between pregnancy days 20 and 40, as well as between anestrus and pregnancy days 20, 40, and 55 (Table 5). The analysis of the circadian rhythm of the minimal, mean, and maximal heart rates showed them to decline from 7:00 p.m. and rise from 7:00 a.m.

\section{DISCUSSION}

The plasma volume expansion that accompanies canine gestation seems to be high enough to cause variations in blood pressure. However, a less marked activation of the renin-angiotensin-aldosterone system, the refractoriness to angiotensin II and other vasoconstrictor agents owing to the effects of vasodilatative prostaglandins may result in a minor decrease of peripheral vascular resistance in this species, therefore resulting in an unchanged blood pressure in spite of increased plasma volume. Also, baroreceptors may play a role in controlling arterial pressure during gestation, as observed by Conrad \& Russ (1992), although it is still unclear if their effect on blood pressure is either up- or downregulated. Circadian variations may be implicated in the variations of arterial pressure in response to vagosympathetic stimulation during the estrous cycle, especially along gestation. Although this parameter did not vary in this investigation, Brooks \& Keil (1994) demonstrated a progressive reduction in the invasive blood pressure recorded in pregnant dogs, particularly between pregnancy days 54 and 60. On the contrary, the same authors did not find any reduction in the non-pregnant bitches, which might explain the elevation of heart rate documented in the animals of this investigation.

No significant variations were observed in the echocardiographic data along the estrous cycle. These results remained within the normal limits, which is likely attributa- ble to the effects of effective neurohumoral compensatory mechanisms, contrasting with women's gestation, where elevated cardiac output, end-diastolic volume, and stroke volume have been shown in response to the augmented plasma volume (Mashini 1987, Metcalfe 1988, Seely \& Moore 1994).

No variation was observed in the ECG-derived heart rate in either group. Nonetheless, the holter assessment disclosed a progressive increase in the minimal and mean heart rates along gestation, as well as a reduction during anestrus in all studied periods. These findings are in agreement with Stein et al. (1999) and are attributable to the changes in the cardiovascular system associated with embryo development (Capeless \& Clapp 1989, Stein et al. 1999). On the other hand, this study showed no need of hemodynamic support in the second third of anestrus, since the minimal, mean, and maximal heart rates returned to baseline values, similarly to the findings of Clapp \& Capeless (1997) in women.

The circadian rhythm of bitches was different between gestation and anestrus. In this setting, the minimal heart rate at gestation day 55 was greater, which might be ascribed to either the reduced parasympathetic stimulation that accompanies gestation (Ekholm 1997) or the sympathetic stimulation itself, precluding the minimal heart rate to drop so dramatically, which could compromise cardiac output. On the contrary, there is an activation of parasympathetic tone during anestrus, since the cardiovascular system needs no adaptation comparable to those that occur along pregnancy (Stein et al. 1999).

The lowest means of the minimal heart rate represent episodes of bradycardia and were documented at night during anestrus, supposedly during the paradoxical sleep. According to Guyton \& Hall (1996), the sympathetic activity decreases while the parasympathetic activity increases during sleep. Also, the higher values of the maximal heart rate were recorded during anestrus, which may indicate a marked sympathetic tone, as well as a disparity of the autonomic nervous system regarding its chronotropic activity. Concerning the maximal heart rate, its inferior values were identified during pregnancy as compared to anestrus. This is likely attributable to a vagal control of heart rate aiming at avoiding any elevation that might be deleterious to the cardiovascular system in relation to the increased hemodynamic demand. A similar vagal activity on the circadian rhythm has been described in patients with cardiac disease (Ekholm et al. 1997).

The low amplitude $\mathrm{P}$ waves seen during gestation might be credited to the augmented abdominal volume, and the impaired body surface electrical conductivity (Tilley 1992) owing to the gravid uterus. The increased QRS complex duration documented during the estrus of group II animals might be related to technical differences in the recording of computer-based electrocardiogram, which was previously demonstrated to be more sensible than the standard paper equipment (Wolf et al. 2000). The assessment of cardiac rhythm showed normal results for canines, except for sinus tachycardia, which indicated moments of excitation in some subjects. Finally, the dramatic variation of $\mathrm{T}$ wave 
polarity documented in this investigation may represent a normal finding. Tilley (1992) indicated that polarity changes could be attributable to physiologic conditions, including respiratory sinus arrhythmia.

The main limitation of this study relies on the small number of animals enrolled, as well as the absence of a more detailed cardiac assessment. In this regard, the inclusion of tissue Doppler imaging could better evaluate heart function, particularly the diastolic component, which is likely to be influenced by volume expansion during gestation. Also, biomarkers could indicate whether either myocyte lesions or hyperdistension are a concern during the canine pregnancy.

A progressive increase in heart rate was observed along gestation, with the values returning to the physiological range in anestrus. On the contrary, the circadian rhythm of heart rate behaved similarly during both pregnancy and anestrus, although the higher values were documented in awake animals as compared to sleeping dogs. Since no important alterations have been demonstrated in the electrocardiographic and systemic arterial pressure data during the phases of the reproductive cycle, it is likely that compensatory mechanisms played a role in maintaining body homeostasis. However, further prospective studies might provide a better understanding of the cardiovascular neuroendocrine events that accompany the canine pregnancy.

\section{REFERENCES}

Banzatto D.A. \& Kronka S.N. 1992. Experimentação agrícola. Funep, Jaboticabal.

Boon J. \& Wingfield W.E. 1983. Echocardiographic indices in the normal dog. Vet. Rad. 24:214-221.

Brooks V.L. \& Keil L.C. 1994. Hemorrhage decreases arterial pressure sooner in pregnant compared with nonpregnant dogs: role of barorreflex. Am. J. Physiol. 266:H1610-H1619.

Capeless E.L. \& Clapp J.F. 1989. Cardiovascular changes in early phase of pregnancy. Am. J. Obstet. Gynecol. 161:1449-1453.

Clapp J.H. \& Capeless E.L. 1997. Cardiovascular function before, during, and after the first and subsequent pregnancies. Am. J. Cardiol. 80:14691473.

Ekholm E.M.K., Piha S.J., Antila K.J. \& Erkkola R.U. 1997. Cardiovascular autonomic reflexes in mid-pregnancy. Brit. J. Obstet. Gynecol. 100:177-182.
Conrad K.P. \& Russ R.D. 1992. Augmentation of barorreflex-mediated bradycardia in conscious pregnant rats. Am. J. Physiol. 262:R472-R477.

Gomes F.P. 1987. Curso de Estatística Experimental. Nobel, São Paulo.

Greene S.A. 1995. Anesthetic considerations for surgery of the reproductive system. Sem. Vet. Med. Surg. Small Anim. 10:2-7.

Guyton A.C. \& Hall J.E. 1996. Tratado de Fisiologia Médica. Guanabara Koogan, Rio de Janeiro.

Hansen B. 1995. Blood pressure measurement, p.110-112. In: Bonagura J.D. \& Kirk R.W. (Eds), Kirk's Current Veterinary Therapy. 12th ed. W.B. Saunders, Philadelphia.

Horwitz K.B. \& Horwitz L.D. 1982. Canine vascular tissues are targets for androgens, estrogens, progestins and glucocorticoids. J. Clin. Invest. 69:750-758.

Kienle R.D. \& Thomas W.P. 1995. Echocardiography, p.198-255. In: Nyland T.G. \& Matoon J.S. (Eds), Veterinary Ultrasound. W.B. Saunders, Philadelphia.

Mashini I.S., Albazzaz S.J., Fadel H.E., Abdulla A.M., Hadi H.A., Harp R. \& Devoe L.D. 1987. Serial noninvasive evaluation of cardiovascular hemodynamics during pregnancy. Am. J. Obstet. Gynecol. 156:1208-1213.

Metcalfe J. 1988. Maternal physiology during gestation, p.2145-2176. In: Knobil E., Neil J.D. \& Myers S.A. (Eds), The Physiology of Reproduction. Raven, New York.

Miller M.W. 1998. The technique of cardiac ultrasound and its applications in clinical practice, p.1-26. In: Sociedade Brasileira de Cardiologia Veterinária (Ed.), Curso Atualização em Ecocardiografia de cães e gatos. SBCV, São Paulo.

Murray E.Z. 1998. Monitoramento não-invasivo da pressão arterial, p.500504. In: Wingfield W.E. (Ed.), Segredos em Medicina Veterinária. Artmed, Porto Alegre.

Seely E.W. \& Moore T.J. 1994. The renin-angiotensin-aldosterone system and vasopressin, p.100-118. In: Tulchinsky D. \& Little A.B. (Eds), Endocrinology. 2nd ed. W.B. Saunders, Philadelphia.

Stein P.K., Hagley M.T., Cole P.L., Domitrovich P.P., Kleiger R.E. \& Rottman J.N. 1999. Changes in 24-hour heart rate variability during normal pregnancy. Am. J. Obstet. Gynecol. 180:978-985.

Tilley L.P. 1992. Essentials of canine and feline electrocardiography. 3rd ed. Lea and Febiger, Philadelphia. 470p.

Vannucchi C.I., Satzinger S. \& Santos S.E.C. 1997. Técnica de citologia vaginal como método de diagnóstico da fase do ciclo estral em cadelas. Clin. Vet. 2:14-19.

Ware W.A. 1998. Diagnostic tests for the cardiovascular system, p.13-47. In: Nelson R.W. \& Couto C.G. (Eds), Small Animal Internal Medicine. 2nd ed. Mosby, St Louis.

Wolf R., Camacho A.A. \& Souza R.C.A. 2000. Eletrocardiografia computadorizada em cães. Arq. Bras. Med. Vet. Zootec. 5:610-615. 